\title{
Complex Communication in the Foreign Language Classroom: Hopes of Turn for the Better
}

\author{
Irina N. Lazareva \\ Far Eastern Federal University, Vladivostok, Russia
}

\begin{abstract}
An impetus given to this study is the commitment to make a real difference to skills and capacity gained through education. The main purpose of this paper is to articulate the concept of complex communication and elicit its potential for making progress in the global environment. In the focus of attention is an essential condition fundamental to students' active and productive participation in intellectually challenging language activities. The study examines how well the students are prepared for complex communication and brings to light generic difficulties which are certain to result in troubles that young people may have in attempt to contribute to higher-leveled communication. The paper calls attention to creating the context in which learners can develop advanced skills valued in the 21 century.
\end{abstract}

Keywords: complex communication, high-level intellectual performance, higher order questions, students' preparedness

\section{Introduction}

Despite a great deal of debate about whether to call 21st century skills an artificial concept or a vital necessity for surviving in the global age, the idea of cultivating certain competences that are critical for collective and individual success in today's world brings together views and aspirations of business leaders, politicians, employers, and educators. Education and effort to reform it place the emphasis on high expectations for intellectual challenge in the classroom (Conceptual foundation..., 2014; Marzano, Yanoski, Hoegh, \& Slimms, 2013). For their part, educators face enormous challenges in delivering future survival skills to students. Therewith you may notice that educational industry sometimes is more fascinated with technology and less concerned about people—details of human learning, students' preparedness, and their potentials development.

\section{Learning-Centered Approach}

Constructionism-based theories have triggered a paradigm shift in the education process towards learning-centered mission of education. The concept of the learning-centeredness places learning first and represents a significant dedication to generate a higher intellectual return from education (Blumberg \& Everett, 2005). The assumption is that student-centered learning activities can give exactly what was wanted for education quality change insofar as it relates to raising students' intellectual standards and strengthening complex thinking abilities. Adding learning-centered values to the program statements will be promotive for students to learn to interact with each other, practice using ways of thinking in the discipline, and develop learning skills for further

Irina N. Lazareva, associate professor, Ph.D., School of Regional and International Studies, Far Eastern Federal University. 
learning (Weimer, 2002). Embedded with this approach is a concept of advanced skills that enable a learner to meet the challenges of and opportunities of rapidly developing society, economy, and environment.

The cognitive key to College and Career Readiness elicited by Dr. David T. Conley (2013) comprises critical thinking, problem solving, collaboration and effective communication skills and dispositions. In recognition of the fact that obtaining this survival package is critically important to graduate competitiveness and competency in today's world, the Far Eastern Federal University (FEFU) as a key-capacity building institution, hopes that new generation of students will have a high level of attainment in them. Therefore, opportunities need to be created and acted.

To improve the landscape of academic training, Education Programs and Technologies Department, with a view of creating lifelong learners, knowledgeable thinkers, and effective communicators, offered FEFU institutions opportunities to adopt the best new ideas and have a share in "Creating Innovative Training for 21 Century Specialists” program, requiring some form of focused practical actions alongside specialist subject knowledge. This initiative has sensitized the faculty to curriculum change to the advantage of active learning methods and development of instructional materials designed to facilitate productive thinking in undergraduate students.

The FEFU university has a communicative approach to foreign language (FL) teaching which is objective driven. This time, high priority has been given to engaging students in higher cognitive level communication which makes a real difference in rising prospective professionals to the challenging work. For turning a classroom into activity-based space, a hard line of active learning practices was assigned to be used intensively on a scheduled basis: exploratory and academic discussions, assigned reading dispute, problem solving team meeting, high-stakes writing, simulation, empathetic interview, mock trial. They can be described as improvisational activities that require intellectual flexibility, an openness in ideas, an ability to "think out of the box". Incorporated authentic intellectual activities are intended to develop a broad array of universally acknowledged generic and work-related competences necessary to interact with people in diverse environments.

\section{Research Question}

The requirement to use language to think beneath the surface means that students are expected to exhibit intellectual capacity to efficiently participate in the complex communication activities. Most of the activities charged with hope of elevating educational background, require students to think at a higher end of cognitive taxonomy. Therefore, if the students are expected to actively participate in the open-ended activities of mind they should be safe in the knowledge and preparedness for this level intellectual performance. In order to generate a clear picture of whether complex communication target level objective is in congruence with students' ability-status, a small-scale investigation was initiated. The research question was:

How well are the students prepared to efficiently participate in the complex communication activities to the effect of taking full advantage of intellectually challenging practices along with making maximal use of their own intellectual capacities?

\section{Review of Literature}

The theme of complex communication is an important learning goal that promotes student success in college and careers (Partnership for 21st Century Skills, 2010). As well as in the case of other pedagogic innovations the concept “complex communication” is non-pedagogic. According to Shedrovitskiy’s (1999) 
logic of reasoning, it was detected in philosophy or socio-cultural sphere, assigned a pedagogic meaning and brought to pedagogy which in this regard serves as a ground for intellectual investment. When integrating Popper's (1971) views of critical analysis, intellectual capacity and joint discussion as essential devices for building an open society with socio-cultural deliberations about development options for improving local and global communities (Pocheptzov, 2001; Sorina, 2009), inference should be drawn that relevant to social advancement is the type of communicative relations that develop facilities for building-up crucial fields of human functionality to shape the way for culture and civilization through implementing various forms of intellectual activity. As opposed, trivial communicative events function in mode of "perpetuating existing information and presuppose wasteland in all areas of life” (Sorina, 2009, p. 58). As far as complex communication is a complex intellectual activity, it involves complex thinking and can be attributed to high-cognitive level performance which involves a broad array of core thinking skills and processes.

\section{Questioning as the Wellspring of Intellectual Excitement}

Indispensable component part of a communication act is ability to initiate questions. In classroom interaction, student participation is promoted through questions that act as stimulation and guiding force setting the pattern and shaping the fundamental nature of the discourse. In addition to its prominence in FL classroom, questioning is the issue of paramount importance on the labor market.

Wagner's research on the skills to be a good citizen and build successful career presented the evidence that the most eagerly sought-for skill in the world of work is "asking good questions" insomuch as "We can teach them the technical staff, but we can't teach how to ask good questions-how to think", say business and nonprofit leaders (Wagner, 2008, p. 21). As for other skills—critical thinking, working with others in team, engaging in discussion, engaging customers, reference is made toward higher-order communication with integral component of producing questions.

Questions can be categorized in terms of their function and purpose. There are a number of question classification systems (Barners, 1969; Mills, Berliner, Rice, \& Risseau, 1980; Nuttal, 1982; Gull, 1984; Graesser \& Person, 1994; McKenzie, 2003) given different names by different scholars which overlap at times. In the methodological materials, questions are commonly categorized into closed and open-ended (Schuman \& Presser 1979; Hanson \& Wolfskill, 2000) though this categorization suggests oversimplification as does not produce the intended effect sufficiently.

Closed questions motivate less communicative involvement (Chaudron, 1988) and require little original thought. They may also be referred to as display/factual/surface questions. The term with which this study is concerned is data-gathering questions (Costa \& Kallic, 2008). They are designed to draw information and look for anticipated response (see Example (1)).

Example (1) When did it happen?

How many people work in the area of social work?

Open-ended is an umbrella term for "outside fact"/referential questions. These questions need more than mechanical searching for an answer. They help to elicit concepts and ideas and require answers produced by students themselves (see Example (2)). In this way, they enable students to be more productive. The term with which this study is concerned is processing questions which as described in Costa and Kallic (2008), "are designed to process information and make meaning of the data” (p. 138).

Example (2) Why did it happen? What are some of the reasons of going into area of social work? 
Alongside data-gathering and processing questions, Costa and Kallic (2008) distinguish the category of questions that apply concepts in new situations (see Example (3)). These questions can be called transfer questions, which require students to reason outside the scope of the given situation.

Example (3) What would we have to do to change this state of things?

In keeping with the goal orientation of elevating intellectual quality of communicative tasks and activities, it is more consistent to turn to classifying questions by reference to the level of cognitive procession they trigger. According to the complexity of thinking, questions are grouped into low-leveled and high-leveled. Lower cognitive questions (Mills et al, 1980)/low order (Wilen, 1991) questions involve low cognitive operations. Higher cognitive/higher-order questions emphasize high levels of thought. They make students go through higher-order mental processes of analyzing, interpreting, restructuring, and making inferences.

Reciprocally, self-explanatory name for complex questioning procedure gives accent to complex thinking involved, i.e., requiring kinds of reasoning as a thinking method of posing and responding to the question (Gage \& Berliner, 1998); encouraging learners to bring their own thoughts and recollections into conversation and investigation inquiry (Burns, 1999); fostering effort and depth of processing in the learners (Thornbury, 1996); calling for assessment and judgment (Cullen, 1998). Conceptual differences representing division between the two broad categories of questions are summarized in Table 1.

Table 1

A Summary of Question Categorical Differences

\begin{tabular}{|c|c|c|}
\hline Question class & Closed-ended & Open-ended \\
\hline Variations & $\begin{array}{l}\text { display questions } \\
\text { factual questions } \\
\text { data-gathering questions }\end{array}$ & $\begin{array}{l}\text { analytical questions } \\
\text { referential questions } \\
\text { processing questions } \\
\text { transfer questions } \\
\text { insightful questions } \\
\end{array}$ \\
\hline Aimed at & $\begin{array}{l}\text { drawing information } \\
\text { looking for anticipated response }\end{array}$ & $\begin{array}{l}\text { building deep understanding; } \\
\text { make meaning of the data }\end{array}$ \\
\hline Defining characteristics & $\begin{array}{l}\text { detail-oriented } \\
\text { surface } \\
\text { shallow }\end{array}$ & $\begin{array}{l}\text { “Outside fact” questions, thoughtful, } \\
\text { penetrating, probing, substantive, incisive }\end{array}$ \\
\hline Focus on & rehearsing information & $\begin{array}{l}\text { - independent thinking; } \\
\text { - students' productivity }\end{array}$ \\
\hline Type of response required & $\begin{array}{l}\text { - in search of facts, experience } \\
\text { - immediate response } \\
\text { - one-surface, obvious answer }\end{array}$ & $\begin{array}{l}\text { - in search of ideas/opinions } \\
\text { - think time is necessary } \\
\text { - under-the-surface answer } \\
\end{array}$ \\
\hline Thinking method involved & $\begin{array}{l}\text { - Observing } \\
\text { - organizing }\end{array}$ & $\begin{array}{l}\text { - Information processing } \\
\text { - Complex reasoning } \\
\text { - Generating and integrating } \\
\text { - Metacognition } \\
\end{array}$ \\
\hline Type of learning motivated & $\begin{array}{l}\text { - recognition and recalling; } \\
\text { - little communicative involvement }\end{array}$ & $\begin{array}{l}\text { Inquiry } \\
\text { Complex communication } \\
\text { Lifelong learning }\end{array}$ \\
\hline Importance & Limited educational value & $\begin{array}{l}\text { Developing the habits needed for academic, } \\
\text { professional and personal success }\end{array}$ \\
\hline Level of thinking involved & Low-order thinking & Higher order thinking \\
\hline
\end{tabular}

Recognizing questioning as a communication "part-skill” (Littlewood, 1992) that draws speakers into conversation and stimulates the production of oral discourse inviting new thoughts and new meanings, this method was chosen as a an object matter and test tool of action research on students' questioning abilities in the FL classroom. 


\section{The Study}

Action research is a realistic extension of professional development (Burns, 1999) and a contributor to accomplishing social tasks. Action research can be described as a contextual, small-scale, and localized study, which investigates a problem within a specific situation. This form of research is not an end in itself. It is aimed at bringing about change and improvement in English as a Foreign Language (EFL) practice.

The purpose of this study was to inquire how well the students were prepared for complex communication activities that require a certain level of proficiency in asking questions engaging mental operations at a higher end of cognitive taxonomy (information processing, inference, complex reasoning, evaluating, interpreting).

\section{Participants}

The study was conducted with two groups composed of 13 and 11 students. The population for this study consisted of second-year students, taking EFL course and possessing proficiency in English. EFL classes refer to those given to help students improve their second foreign language skills to maintain communication in English in diverse environments.

\section{Procedure}

A test on "Formulating good questions" was administered, in which the students were assigned the three items aimed to appraise their questioning abilities.

Items 1 and 2 contained external reality (environment around the student's mind) content for phrasing questions.

Item 1 was aimed at examining and finding meaning in the visual image on "Getting into Accident" topic. Item 2 was aimed at creating questions about a reading text concerning eco-life ("Spinning a Web of Walkways").

The questions generated in test item 3 addressed a student's personal reality content (environment inside the student's mind). It was a task in the form of self-directed interview. Each student wrote down the questions that (s)he would like to be asked in the context restricted to the area of Jobs and Professions.

The students were given a certain amount of time (40 minutes) to think over phrasing "good questions".

\section{Data Collection}

The qualitative data were collected through the questions supplied to the test provided as preliminary investigation if students complex communication skills ability. The number of student-generated questions was counted and their types were determined. Each question was estimated by the criterion of question categorical format provided above. It was distinguished a sublevel of questions that had not been identified in the materials before the class procedure. On the one hand, the questions produce dare thought-provoking, on the other hand, these questions are just imaginative and do not stimulate great effort.

What is the police officer writing in his notebook?

How much would the car maintenance cost?

What punishment is OK for this offence?

How would you feel if you were involved into in such a situation?

Why do some people spend too much time in their workplace?

The questions that refer to this group trigger speculative thinking, a type of thinking based on arbitrary assumptions. The effort involved in asking and answering speculative question does not stimulate depth or require reasoning so they were referred to low-cognitive level group of questions. Table 2 summarizes the data 
interpretation results.

Table 2

Distribution of Students' Questions

\begin{tabular}{|l|l|l|l|}
\hline \multicolumn{2}{|l|}{ Total number of questions: 596} & \multicolumn{2}{l|}{} \\
\hline $\begin{array}{l}\text { Number of data-gathering } \\
\text { questions }\end{array}$ & $\begin{array}{l}\text { Number of speculative } \\
\text { questions }\end{array}$ & $\begin{array}{l}\text { Number of processing } \\
\text { questions }\end{array}$ & Number of transfer questions \\
\hline Lower-cognitive level & Higher-cognitive level & 6 \\
\hline 525 & 53 & 12 & \\
\hline
\end{tabular}

The analysis of quantitative data indicated that out of 596 questions asked during the test, 525 were data-gathering questions (88\%), 53 were speculative ones (9\%), 12 of the total were processing questions (2\%), six were transfer questions (1\%).

It can be concluded that observed students asked a good deal more lower-cognitive questions than higher order questions whether addressing external or internal reality content. The percentages of the number of lower-cognitive level and higher-cognitive level questions are shown in Figure 1.

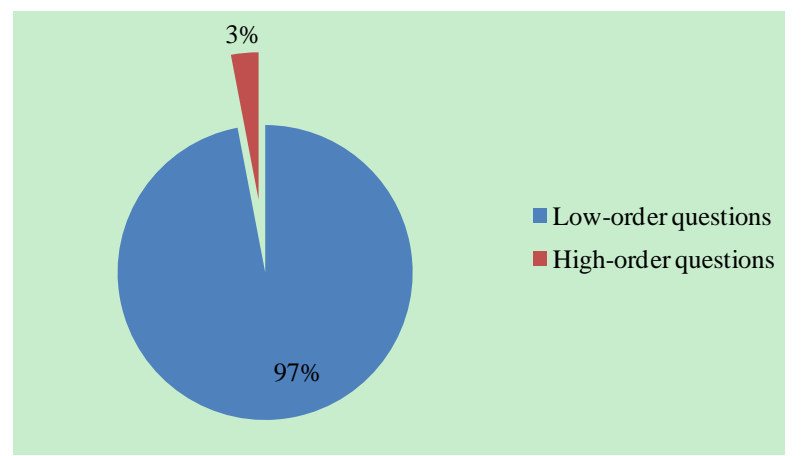

Figure 1. Pie chart to show percentages of higher and lower order questions.

\section{Results}

The question posed in this case study was: How well are the students prepared to efficiently participate in the complex communication activities to the effect of taking full advantage of intellectually challenging practices along with making maximal use of their own intellectual capacities?

The analysis of the students' questioning ability selected as a part skill of not specified communication and, a high-level questioning ability in particular, as a target complex communication strategy, allowed to make the following observation.

The action-research evidentiated that students could formulate mostly factual and speculative questions, which is not sufficient for complex communication proficiency. Therefore, the second-year students are trained for meaningful communication activities on a personal level (sharing of information, feelings, ideas). However, they are not skilled enough to efficiently participate in the complex communication activities that require higher-order thinking instrumentality.

\section{Discussion}

Conspicuous is the fact that higher-level language learners used though carefully worded, but principally factual, closed questions of low cognitive level. Students ask these questions because in the actual practice FL 
instruction teaches mostly the mechanics of questioning in the target language and does not teach higher-order question skills. Consequently, this class of questions does not exist in students' schemata. The categories of abstract thinking represent innovative elements in FL syllabus specifications so far and are often neglected because teachers think that students can develop this ability unassisted.

There is no exception for Intensive FL Complex Communication Practice program - from the undertaken study follows the pre-requisite that intellectually challenging activities which the program calls for, include many skills not taught or developed explicitly in most training programs. This complicating disorder will make students reluctant to take a part in complex thinking activities, since prospective participants will not possess a certain minimum proficiency.

\section{Recommendations}

Setting an objective of fostering a learned thinker is linked to incorporating cognitive development component, which introduces another layer of complexity onto communication-related classroom. Providing not just useful (nobody doubts that experience of high intellectual quality is useful) but relevant practice (when students are able to efficiently fulfill the task) is a factor that contributes to the effectiveness of complex communication language lesson. Based on the discussion above the following strategies were devised to provide the impetus for change.

(1) In the communication that appeals to intelligence transmission, questioning is the language activity of producing oral discourse that invites taking new thoughts and new meanings, and as work tools of communication are bound up with higher cognitive functions. Thus, asking higher-level questions activates thinking and reasoning and makes students behave at relatively higher levels of cognitive processing. Hence, it appears that having students ask questions that are assumed to trigger complex communication without teaching the instrumentality of higher-order questioning may not be effective.

(2) Higher order "part-skills" of communication can be improved through focused instruction. A teacher should be aware of the skills necessary for students to complete a high-level thinking communication task at an adequate level. The broader spectrum of skills a student can use efficiently to complete a task, the better quality is implied (Ennis, 1997; Lipman, 2003).

(3) In order to ensure that teaching of complex questioning skills will deliver benefits, explicit instruction is needed to provide learners with an awareness—raising package of process strategies and complex thinking skills.

Thus, creating an intellectually sensitive environment can become a key factor for students' willingness to communicate at a higher level of cognitive complexity.

\section{Conclusion}

The emphasis of education is no longer the importance of knowledge and definite answers but developing higher order thinking and open-ended questions.

The action-research described above shows that it is important to teach students higher-order questions which are necessary for communicative purposes and prospective research projects as well.

Though, with all these things considered, complex communication practice can become an irreplaceable experience of high intellectual quality only if students are geared up to use their minds well just as teachers are prepared to teach in ways the new-day standards expect. 


\section{References}

Barnes, D. (1976). From communication to curriculum. Harmondsworth, UK: Penguin.

Blumberg, P., \& Everett, J. (2005). Achieving a campus consensus on learning-centered teaching: Process and outcomes. To Improve the Academy, 23, 191-210.

Burns, A. (1999). Collaborative action research for English language teachers. Cambridge: Cambridge University Press.

Chaudron, Ch. (1988). Second language classrooms: Research on teaching and learning. Cambridge, UK: Cambridge University Press.

Conceptual Foundation of Federal Targeted Program for education advancement for the period of 2016-2020. (2014). Retrieved from http://government.ru/media/files/mlorxfXbbCk.pdf

Conley, D. T. (2013). Getting ready for college, careers and the Common Core: What every educator needs to know. New York: Jossey-Bass.

Costa, A. L., \& Kallic, B. (2008). Using questions to challenge students' intellect. In A. L. Costa \& B. Kallic (Eds.), Learning and leading with habits of mind: 16 essential characteristics for success (pp. 135-148). Alexandria: ASCD.

Cullen, R. (1998). Teacher talk and the classroom context. ELT Journal, 52(3), 179-187.

Ennis, R. H. (1997). Incorporating critical thinking in the curriculum: An introduction to some basic issues. Inquiry, 16(3), 1-9.

Gage, N. L., \& Berliner, D. C. (1998). Educational psychology (6th ed.). Boston, MA: Hougton Mifflin.

Graesser, A. C., \& Person, N. K. (1994). Question asking during tutoring. American Educational Research Journal, 31, $104-137$.

Gull, M. D. (1984). Synthesis of research on teachers' questioning. Educational leadership, 11, 40-47.

Hanson, D. M., \& Wolfskill, T. (2000). Process workshops-A new model for instruction. Journal of Chemical Education, 77, 120-129.

Lipman, M. (2003). Thinking in education. Cambridge, UK: Cambridge University Press.

Littlewood, W. T. (1992). Teaching oral communication: A methodological framework (applied language studies). Hoboken: Wiley-Blackwell.

Marzano, R., Yanoski, D., Hoegh, J. K., \& Slimms, J. A. (2013). Using Common Core Standards to enhance classroom instruction and assessment. Bloomington: Marzano Research Lab.

McKenzie, J. (2003). Pedagogy does matter! Retrieved from http://fno.org/sept03/pedagogy.html

Mills, S. R., Berliner, D. C., Rice, C. T., \& Risseau, E. W. (1980). The correspondence between teacher questions and students answers in classroom discourse. Journal of Experimental Education, 48, 194-204.

Nuttall, C. (1982). Teaching reading skills in a foreign language. Oxford: Heinemann International.

Partnership for 21st Century Skills. (2010). 21st century readiness for every student: A policymaker's guide. TUCSON, AZ: Author. Retrieved from www.p21.org/storage/documents/policymakersguide_final.pdf

Pellegrino, J. W., \& Hilton, M. L. (2012). Education for life and work: Developing transferable knowledge and skills in the 21st century. Washington, D.C.: The National Academies Press.

Pocheptzov, G. G. (2001). Theory of communication. Moscow: Refl-Book.

Popper, K. R. (1971). The open society and its enemies volume 2: The high tide of prophecy: Hegel, Marx, and the aftermath (5th ed.). Princeton: Princeton University Press.

Schuman, H., \& Presser, S. (1979). The open and closed question. American Sociological Review, 44, 692-712.

Shedrovitskiy, P. T. (1999). Considering the problem of action approach range in education. In Proceedings of Conference on School and Open Society (pp. 4-9). Moscow, Tomsk.

Sorina, G. V. (2009). Decision making as intellectual activity. Moscow: Canon.

Thornbury, S. (1996). Teachers research teacher talk. ELT Journal, 50, 279-289.

Wagner, T. (2008). Rigor redefined. Educational Leadership, 66(2), 20-25.

Weimer, M. (2002). Learner-centered teaching. San Francisco: Jossey-Bass.

Wilen, W. (1991). Questioning skills, for teachers. Washington, D.C.: NEA Professional Library. 